\title{
TRANSFORMACIÓN URBANA, ESPACIO PÚBLICO Y SU PERCEPCIÓN SOCIAL. EL RÍO SEGURAA SU PASO POR ORIHUELA Y ROJALES
}

\author{
Pablo MARTÍ CIRIQUIÁN \\ pablo.marti@ua.es \\ Clara GARCÍA MAYOR \\ magarma@ua.es
}

\author{
Almudena NOLASCO CIRUGEDA \\ almudena.nolasco@ua.es \\ Departamento de Edificación y Urbanismo \\ Universidad de Alicante
}

\section{Recibido: 30/09/2013}

Aceptado: 06/01/2014

RESUMEN: El río Segura en su tramo final, la Vega Baja en la provincia de Alicante, atraviesa las ciudades de Orihuela y Rojales, que se caracterizan por ser las dos únicas de esta zona en las que el cauce recorre su casco urbano. Se parte de las obras de remodelación del cauce con el Plan de Defensa contra Avenidas en la Cuenca del Río Segura, concluido en 1994, en el que la solución adoptada para el encauzamiento en los tramos urbanos es similar en ambos municipios. Esta investigación expone en qué medida dichas actuaciones han tenido un reflejo directo en la imagen de la ciudad, en las actividades en el espacio público urbano y en la manera que es percibido por los ciudadanos. Finalmente, se ponen en evidencia resultados coincidentes y divergentes, pese a la similitud del contexto de las actuaciones.

PALABRAS CLAVE: Orihuela, Rojales, Ciudad, Río Segura, Transformación urbana, Espacio público

1 El presente texto se incardina en el proyecto de investigación Las ciudades españolas en la etapa autonómica (1978-2012). Dinámicas, procesos y políticas (URBSPAIN), financiado por el Plan Nacional de Investigación I+D+i del Ministerio de Economía y Competitividad para el período 2010-2013 (Código CSO 2009-11261-Subpr. GEOG). 
URBAN TRANSFORMATION, PUBLIC SPACE AND SOCIAL PERCEPTION. THE RIVER SEGURA AS IT PASSES THROUGH ORIHUELA AND ROJALES

ABSTRACT: The final part of the Segura River's course flows through the region of the Vega Baja in the province of Alicante. In this area, the river crosses the town centre of Orihuela and Rojales, the only two cities with this condition. In 1994, works of redesign of the route of the Segura river were finished. The aim of these works was to improve the security and protection against flooding. In both cases the channel was re-built following the same constructive solution. This research exposes the way these measures have had a direct impact on the image of these cities, in urban public space activities and in the manner that these interventions were perceived by citizens. Despite the similar context, the results of the research show coincidences and differences between the two cities.

KEY WORDS: Orihuela, Rojales, City, Segura River, Urban transformation, Public space

\section{INTRODUCCIÓN}

Las características orográficas y climáticas de la Comunidad Valenciana la convierten en una de las regiones españolas en las que, además del litoral, las cuencas y ríos que atraviesan su territorio han tenido una especial relevancia en organización territorial y urbana de sus asentamientos.

En el caso concreto de las cuencas y ríos, la definición de sus cauces y áreas de influencia ha estado siempre en las preocupaciones de la planificación territorial y urbana, especialmente por los riesgos de inundación originadas por la irregularidad de las precipitaciones a lo largo del año, con sequías estivales y lluvias torrenciales en los meses de otoño.

Precisamente esas lluvias torrenciales -también llamadas "gota fría"-, características habituales en determinados momentos del año, provocan grandes concentraciones de agua en ríos y ramblas de relativa corta dimensión y fuerte pendiente, provocando grandes crecidas y desbordamientos en poco espacio de tiempo en los tramos más llanos y finales de su recorrido.

A esa circunstancia hay que añadir la realidad territorial de la Comunidad Valenciana, con una configuración de los asentamientos concentrada en áreas costeras y ribereñas de los cauces más importantes; siendo todavía más relevante en las zonas de menor pendiente, territorios donde históricamente el llano ribereño ha sido el suelo más fértil, a la vez que más fácil de colonizar, de ahí que la importancia del tratamiento fluvial se convierte en muy relevante.

Seguramente el ejemplo de encauzamiento más conocido, en este sentido, sea la construcción de un nuevo cauce para el río Turia, tras las inundaciones de la ciudad de Valencia en 1957. Sin embargo, son muchos los ejemplos de actua- 
ciones que han tratado de reducir el riesgo de inundación, o control de riadas en las poblaciones situadas en áreas inundables.

Desde la creación de los gobiernos autonómicos, en la Comunidad Valencia, el riesgo de inundaciones ha sido una de las principales preocupaciones en el ámbito de la planificación territorial. Así, destaca el plan de acción territorial PATRICOVA (Plan de Acción Territorial de carácter sectorial sobre prevención de Riesgos de Inundación en la Comunidad Valenciana), que se aprobó definitivamente en enero de 2003.

En el conjunto de las áreas de riesgo identificadas y evaluadas por el Plan, sobresale por su dimensión y ámbito de afecciones el río Segura; y, a lo largo de su recorrido los dos núcleos urbanos más importantes, por población, extensión y por representatividad histórica, que atraviesa dicho cauce, son Orihuela y Rojales.

Este artículo contextualiza, describe y evalúa la repercusión que las diferentes actuaciones de reestructuración y mejora del cauce del río han tenido desde dos puntos de vista principales: el planteamiento de los técnicos y la percepción de la población en general.

\section{METODOLOGÍA, FUENTES, HIPÓTESIS DE TRABAJO}

\section{II.1 Metodología y Fuentes}

En la metodología planteada para este estudio se parte del análisis inductivo de datos fundamentalmente cualitativos, aunque también se considera la cuantificación de algunos aspectos introductorios y las encuestas realizadas a los agentes implicados. Como método para la investigación se opta por el estudio de casos, dos representativos en esta investigación, para posteriormente elaborar una percepción general del proceso y sus repercusiones (UREÑA, 1999).

Para abordar el estudio de casos en relación con la de los cauces fluviales, se parte de tres tipos de documentaciones que imponen, a su vez, tres tipos de metodología de análisis y estudio. Así, los tres grupos de fuentes documentales utilizadas son: la legislación urbanística, la bibliografía específica relativa a las problemáticas de la cuenca del Segura y las entrevistas o encuestas a los agentes relevantes. 


\section{El planeamiento urbanístico}

En cuanto a la legislación, como se ha comentado, la primera norma urbanística que afecta directamente al ámbito es el Plan de Acción Territorial de Carácter Sectorial sobre Prevención de Inundación en la Comunidad Valenciana (PATRICOVA), como instrumento de ordenación del territorio previsto en la Ley 6/1989 de Ordenación del Territorio de la Comunidad Valenciana.

Los objetivos, enunciados en la memoria del mismo, plantean la evaluación riesgo de inundación - impacto sobre el territorio, proponen una serie de medidas de actuación, tanto para el control como la reducción de las situaciones de riesgo. La articulación de dichas medidas de actuación con el planeamiento municipal y territorial integrado existente, así como el desarrollo de la normativa técnica y de protección aplicable, lleva finalmente a una evaluación del coste de las actuaciones definidas, estableciendo un orden de prioridad de las mismas.

Dentro del diagnóstico que hace el Plan, el río Segura y su área de influencia figuran como uno de los espacios de mayor riesgo de la Comunidad Valenciana por impacto y densidad de población, resaltando que afecta fundamentalmente a los municipios de Orihuela, Almoradí, Callosa del Segura, Dolores, Rafal, Benejúzar, Formentera del Segura, Rojales, Daya Nueva y Daya Vieja. De todos ellos, el presente artículo se centra en Orihuela y Rojales dado que el curso del río atraviesa sus cascos urbanos a su paso, y las medidas tomadas son semejantes, aunque el espacio público urbano junto al río tiene características diferenciadoras.

Tal y como se constata en la figura 1 y el cuadro 1, el ámbito de riesgo de inundación máxima es el que afecta a un área más densamente poblada. Con un Nivel de Riesgo 2, que se refiere a la periodicidad prevista de máxima avenida, entre 25 - 100 años; y un calado superior a $0.8 \mathrm{~m}$, tenemos un área de afección de casi $21.000 \mathrm{Ha}$.

Posteriormente se han desarrollado normativas territoriales, tanto de carácter general como sectorial, que han establecido las estrategias y condiciones de planificación. Entre los planes integrados destaca el Plan de Acción Territorial de la Vega Baja, un planeamiento que regula el desarrollo y transformación de la denominada área funcional dominada por el río Segura, apostando por un crecimiento limitado de las áreas urbanas cercanas al río y defendiendo su carácter compacto frente a la dispersión producida en el entorno litoral (MARTí, 2006). Respecto a la intervención en el río Segura, el plan se remite al mencionado PATRICOVA. 
Recientemente, la Generalitat Valenciana ha apostado por un modelo de planificación que integra los antiguos planes de Acción territorial en la llamada Estrategia Territorial de la Comunidad Valenciana, que se estructura por capítulos correspondientes a objetivos sobre el territorio. El objetivo 8: Minimizar los efectos de los riesgos naturales e inducidos, recoge en la pág. 16 la cartografía de riesgo de inundación; pero, el área de la Vega Baja también está recogida en otros objetivos como el de conectividad del territorio, la infraestructura verde de la Comunidad Valenciana, o los paisajes identitarios de la misma (GENERALITAT VALENCIANA, 2011).

Figura 1: Plano de zonas según riesgo de inundación.

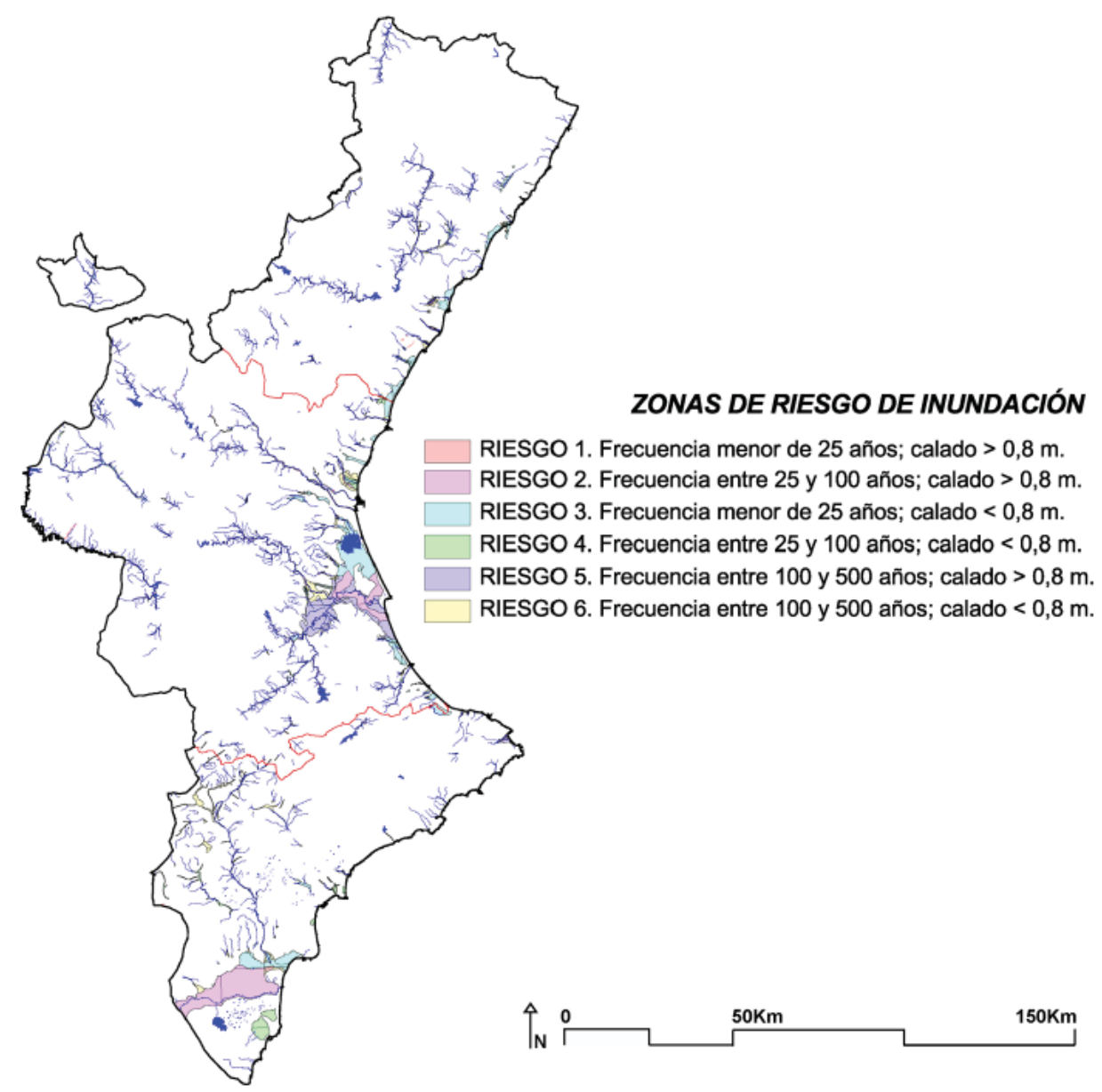

Fuente: Planos PATRICOVA. 
Cuadro 1. Zonas con mayor superficie en riesgo de inundabilidad.

\begin{tabular}{|c|c|c|c|c|}
\hline $\begin{array}{l}\text { Denominación } \\
\text { de la zona de } \\
\text { inundación }\end{array}$ & $\begin{array}{l}\text { Superficie por } \\
\text { Nivel de Ries- } \\
\text { go } 1 \\
<25 \text { años } \\
\text { calado }>0.8 \mathrm{~m}\end{array}$ & $\begin{array}{l}\text { Superficie por } \\
\text { Nivel de Ries- } \\
\text { go } 2 \\
\text { entre } 25-100 \\
\text { años } \\
\text { calado }>0.8 \mathrm{~m}\end{array}$ & $\begin{array}{l}\text { Superficie por } \\
\text { Nivel de Ries- } \\
\text { go } 3 \\
<25 \text { años } \\
\text { calado }<0.8 \mathrm{~m}\end{array}$ & $\begin{array}{l}\text { Superficie por } \\
\text { Nivel de Ries- } \\
\text { go } 4 \\
\text { entre } 25-100 \\
\text { años } \\
\text { calado }<0.8 \mathrm{~m}\end{array}$ \\
\hline $\begin{array}{l}\text { C25 Río Se- } \\
\text { gura }\end{array}$ & & $207.923 .850 \mathrm{~m}^{2}$ & & \\
\hline $\begin{array}{l}\text { VC27 Laguna } \\
\text { de la Albufera }\end{array}$ & & & $98.230 .371 \mathrm{~m}^{2}$ & \\
\hline $\begin{array}{l}\text { VC28 Inun- } \\
\text { dación masiva } \\
\text { del río Xúquer }\end{array}$ & $9.819 .220 \mathrm{~m}^{2}$ & $78.554 .139 \mathrm{~m}^{2}$ & $478.129 \mathrm{~m}^{2}$ & \\
\hline $\begin{array}{l}\text { VI03 Valle del } \\
\text { río Turia }\end{array}$ & $13.150 .595 \mathrm{~m}^{2}$ & $3.085 .700 \mathrm{~m}^{2}$ & $6.386 .250 \mathrm{~m}^{2}$ & $1.172 .407 \mathrm{~m}^{2}$ \\
\hline $\begin{array}{l}\text { VI11 Río Ma- } \\
\text { gro }\end{array}$ & $1.164 .200 \mathrm{~m}^{2}$ & $7.966 .485 \mathrm{~m}^{2}$ & & $17.848 .102 \mathrm{~m}^{2}$ \\
\hline $\begin{array}{l}\text { AC23 Cono } \\
\text { del río Vina- } \\
\text { lopó }\end{array}$ & $3.630 .637 \mathrm{~m}^{2}$ & & $55.311 .086 \mathrm{~m}^{2}$ & \\
\hline $\begin{array}{l}\text { AC26 Salinas } \\
\text { de Torrevieja }\end{array}$ & & & & $35.666 .951 \mathrm{~m}^{2}$ \\
\hline
\end{tabular}

FuENTE: Memoria PATRICOVA. Apéndice nº3 - Riesgos en Zonas de Inundación.

Por último, conviene referirse a los planeamientos municipales que, en definitiva, regulan los usos específicos de los suelos en el ámbito municipal. En el municipio de Orihuela, el P.G.M.O.U. vigente es el aprobado en el año 1990, aunque actualmente se encuentra en proceso de revisión y redacción de un nuevo Plan del que se ha emitido un documento de referencia con fecha de junio 2013. El P.G.O.U de Rojales se aprobó definitivamente en julio del año 2000. En ninguno de los dos planeamientos municipales existe un tratamiento específico de las márgenes urbanas del río.

\section{II.2 HIPÓTESIS DE TRABAJO}

Para abordar el estudio de las intervenciones y sus repercusiones se parte, por un lado, de la representatividad de los dos casos de estudio y, por otro, de los efectos beneficiosos de la integración entre las políticas urbanas a nivel municipal y supramunicipal, en diferentes sectores y a distintas escalas. 
Respecto a las poblaciones, el Rio Segura recorre unos diez municipios, sin embargo, las dos únicas poblaciones en las que el río atraviesa totalmente el núcleo urbano son Orihuela (fig.2 y fig.3) y Rojales (fig.4 y fig.5). Esa condición de ocupación del ámbito urbano central afectando a los dos márgenes del río le confiere al cauce del Segura una condición estructural desde el punto de vista urbanístico, lo que conlleva que cualquier intervención en su cauce y márgenes tenga una enorme repercusión urbana.

La hipótesis de partida de este trabajo es que las intervenciones realizadas en los tramos urbanos del cauce del río han mejorado la relación de la ciudad con el mismo:

1. En el tejido urbano: desde el punto de vista de la mejora de la imagen urbana, redefinición y jerarquización de la red de espacios públicos

2. En el tejido socio - económico: Ubicación de equipamientos públicos que redefinen espacios de encuentro y actividad en la ciudad, y por tanto establecen una mejora de la percepción que los ciudadanos tienen del río, así como la revalorización de dicho espacio como activación de un sector terciario.

3. En la percepción de seguridad frente al riesgo de inundaciones y crecidas del río Segura.

\section{ESTUDIO EMPÍRICO}

\section{III.1 El caso del río Segura a su paso por la provincia de Alicante}

Las crecidas del río Segura están registradas desde 1535 y, del estudio de la serie histórica, se detecta un cierto carácter bienal en las inundaciones producidas. Las riadas e inundaciones más importantes, casi siempre, han estado acompañadas de medidas correctoras de los riesgos (GIL, 1989). Ya en 1886 se redacta el proyecto de defensa de las inundaciones en el del Valle del Segura orientado a la construcción de presas a lo largo de la cuenca para evitar las inundaciones en casos de crecidas y, en 1931, se elabora un plan de aprovechamiento y corrección de ramblas (GómEz, 2008).

Como consecuencia de la tristemente célebre riada de octubre de 1973 se elabora el Plan de Defensa contra avenidas de la cuenca del Segura en 1977. Este plan propone la intervención en tres ciudades, una de ellas en la provincia 
de Alicante, Orihuela, para la que se plantea una posible variante de unos cinco kilómetros a su paso por la ciudad, finalmente no construida.

A pesar de la existencia de este Plan, en 1987 se vuelven a afrontar una nueva serie de medidas correctoras tras las tres inundaciones de la década de los ochenta, en 1982, 1986 y 1987, (GrindLAY, 2007). Especialmente en esta última riada, el 3 y 4 de noviembre de 1987, se alcanzan lluvias de 400 mm en la Vega Baja y se convierte en el detonante para la aprobación de un Real Decreto de medidas urgentes con el fin de reparar los daños causado por las inundaciones en la Comunidad Autónoma Valenciana y en la Comunidad Autónoma de la Región de Murcia en el que, además de paliar los daños causados por las inundaciones se establece un programa de ejecución de obras con un compromiso económico en los presupuestos Generales del año 1987 y siguientes. De hecho, las obras incluidas en este programa se construyeron entre los años 1991 y 2000. La partida económica más importante de este nuevo Plan de Defensa corresponde al encauzamiento del río en los $88 \mathrm{~km}$. que discurren desde Beniel hasta Guardamar del Segura, es decir el tramo correspondiente a su paso por la provincia de Alicante, incluyendo las poblaciones de Orihuela y Rojales.

Figura 2. Fotografia aérea del casco urbano de Orihuela. 1977

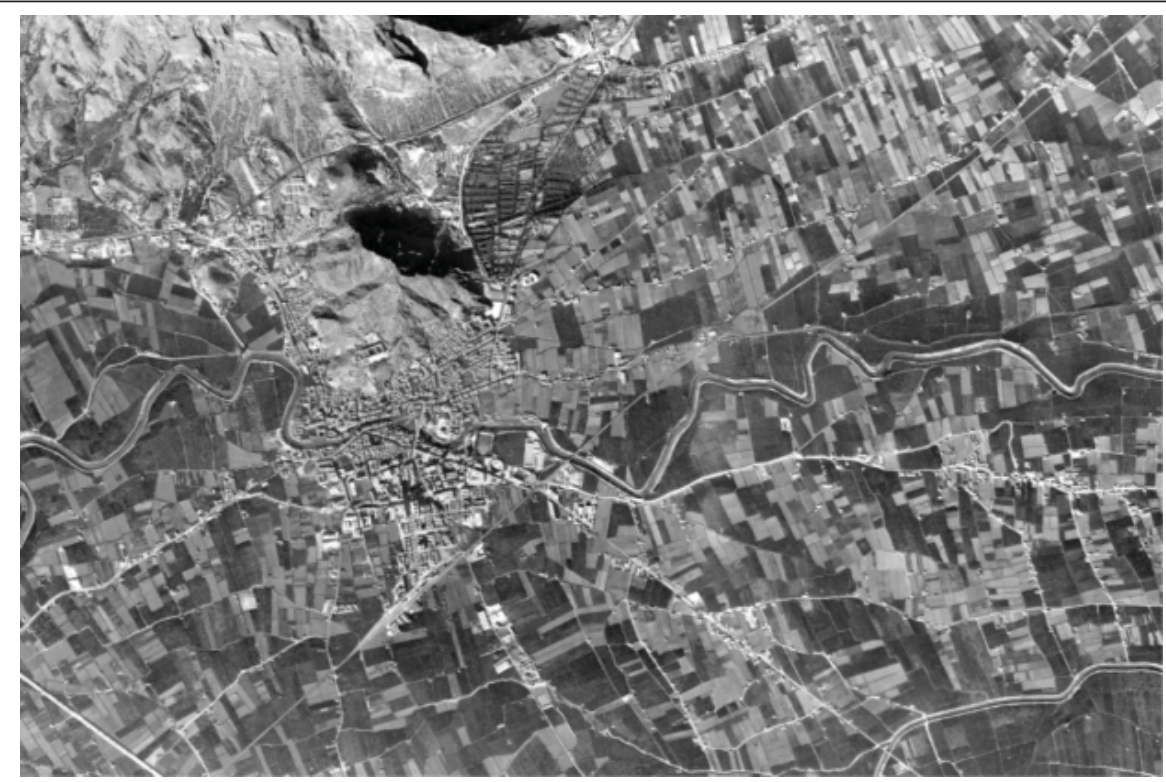

FUENTE: Instituto Geográfico Nacional (I.G.N.) Vuelo interministerial IRYDA. 1977-83. 
Figura 3. Fotografia aérea del casco urbano de Orihuela. 2010.

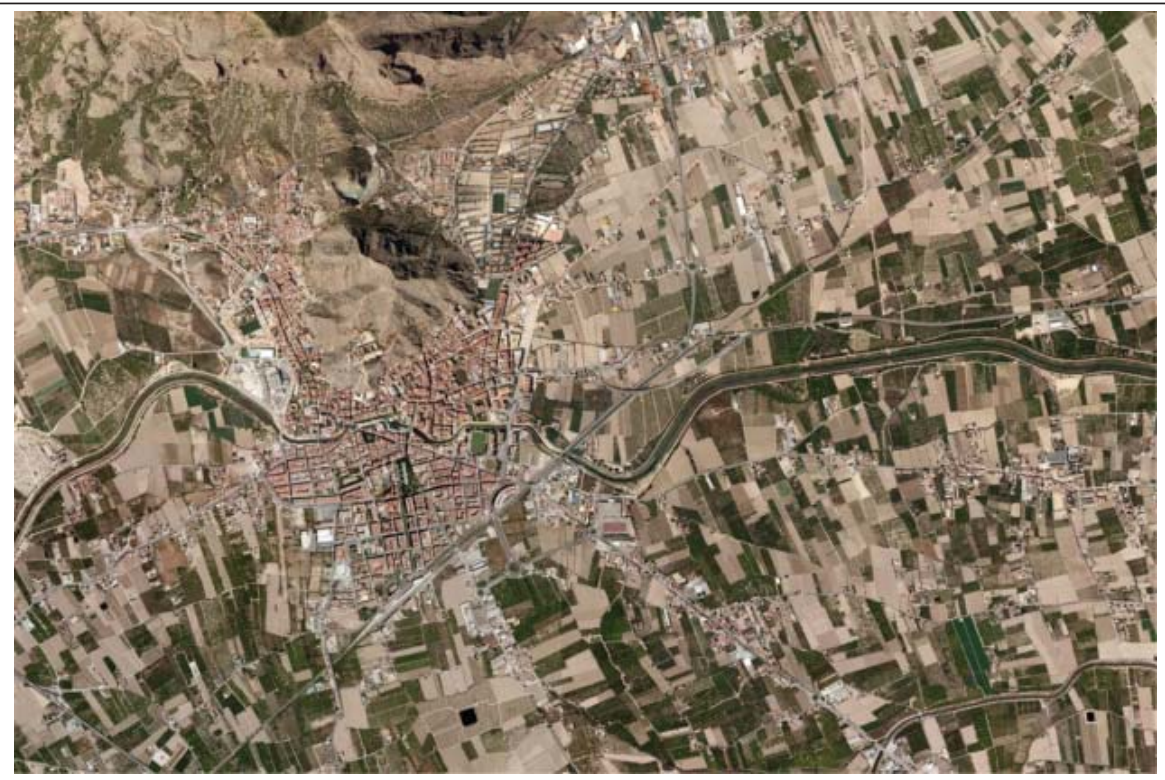

FuENTE: Instituto Cartográfico Valenciano (I.C.V.) Vuelo 2010

Figura 4. Fotografia aérea del casco urbano de Rojales. 1977

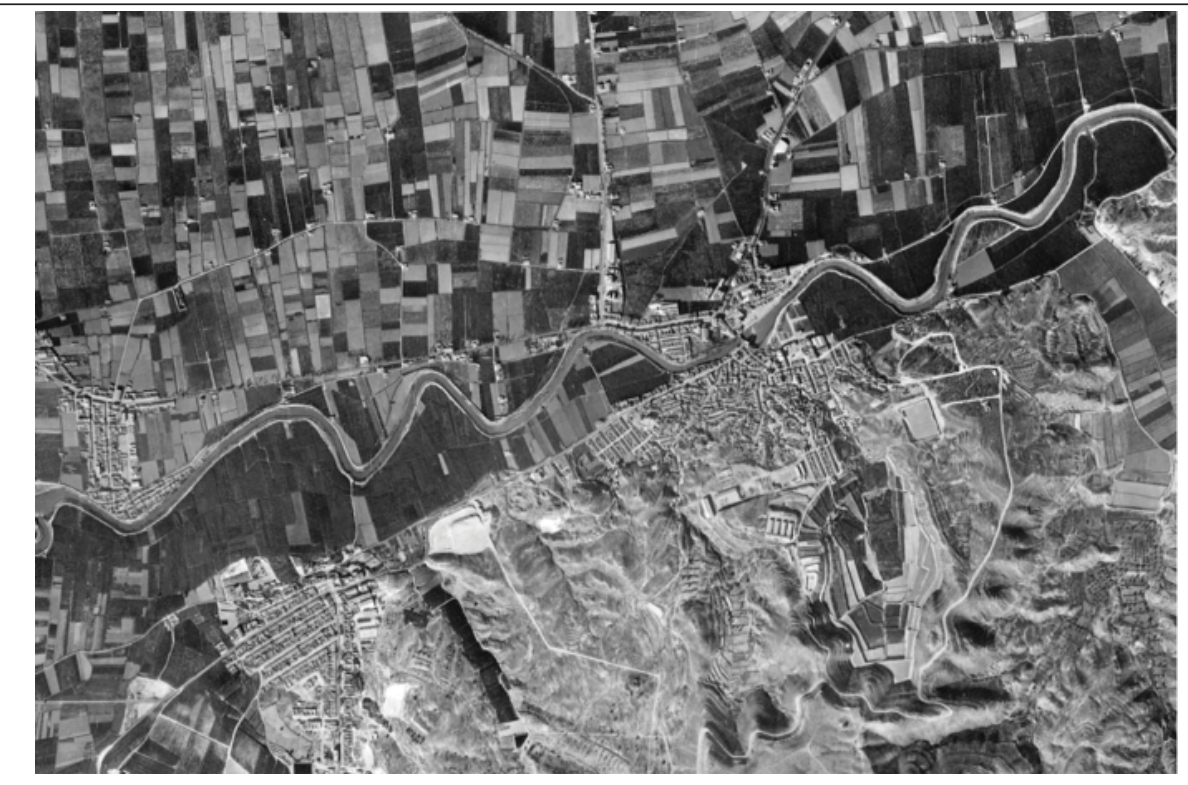

FUENTE: Instituto Geográfico Nacional (I.G.N.) Vuelo interministerial IRYDA. 1977-83. 
Figura 5. Fotografia aérea del casco urbano de Rojales. 2010

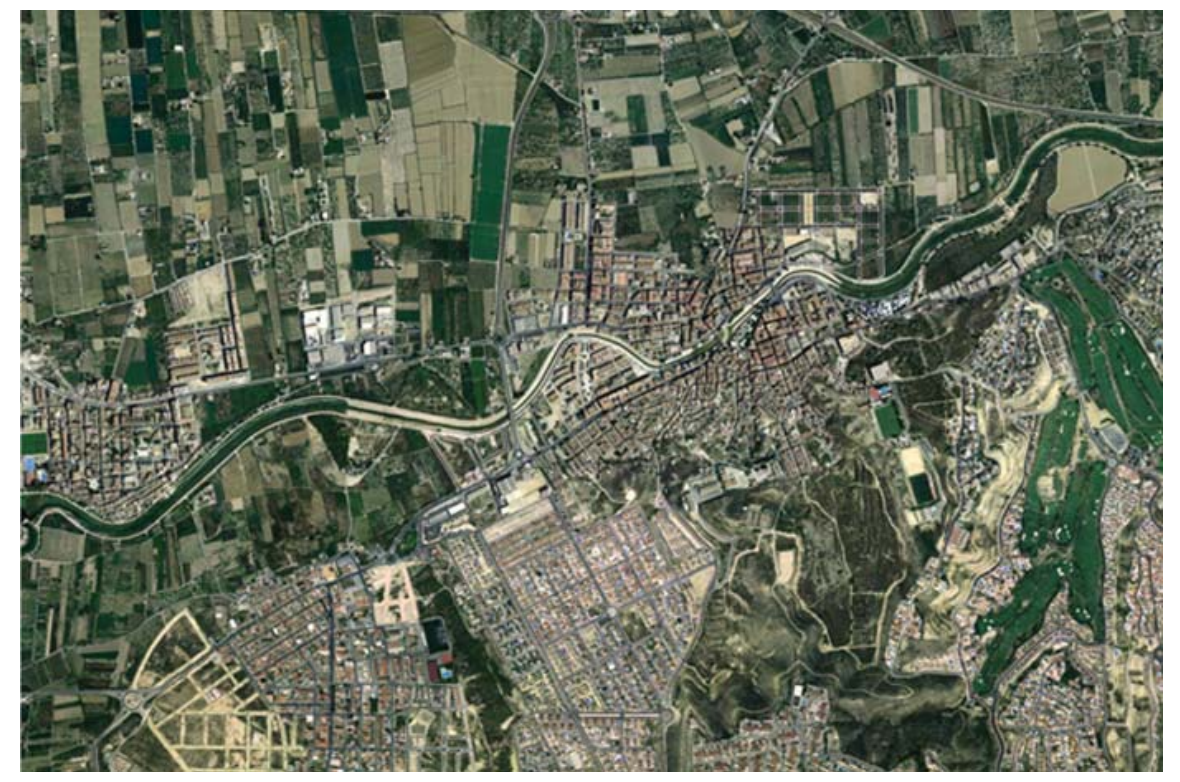

FuENTE: Instituto Cartográfico Valenciano (I.C.V.) Vuelo 2010

Este nuevo cauce se proyecta para un caudal máximo de $400 \mathrm{~m}^{3} / \mathrm{s}$ a su paso por Orihuela y Rojales, una capacidad considerable teniendo en cuenta que antes de las obras el caudal del cauce había quedado reducido a unos $120 \mathrm{~m}^{3} / \mathrm{s}$ en algunos tramos (MuÑoz, 2007). Esta capacidad de caudal se logra mediante dos mecanismos: por un lado, con la construcción de un nuevo cauce mediante obras de fábrica y paneles de hormigón prefabricado; y, por otro lado, mediante la regularización de la pendiente de los tramos existentes aguas abajo de estas dos ciudades. En este segundo sentido, se suprimen muchos de los meandros existentes a lo largo del trazado, como se aprecia en las figuras 2 a 5 .

Toda la obra ejecutada se plantea para un periodo de retorno de 50 años, un periodo que puede ser considerado escaso si atendemos a la densidad de población existente en el ámbito pero que se sitúa en los límites de las posibilidades de la topografía y condiciones del territorio. También se modifica sustancialmente el recorrido del río ya que, desde la Contraparada de Murcia hasta la desembocadura en Guardamar del Segura, de los 88.263 metros de longitud existentes antes de la intervención se reducen a 63.277 m., es decir, una disminución del 28,5\% de su longitud, con el consecuente aumento de la pendiente media del río. 
El proceso de redacción de los proyectos del nuevo cauce del Segura sigue una serie de fases que permitió un proceso de participación pública y la introducción de mejoras en sucesivas etapas. Así, inicialmente, se acomete un anteproyecto denominado "Análisis del encauzamiento del río Segura entre Murcia y Guardamar. Alicante y Murcia" que fue expuesto a información pública con el objetivo de enriquecer los proyectos de construcción a través de las alegaciones presentadas. Los agentes sociales y entidades que participaron en ese proceso incluyen tanto a organizaciones vinculadas al uso agrícola -Comunidades de Regantes, Juzgados de Aguas-, administraciones públicas- Ayuntamientos, Diputaciones provinciales y Comunidades Autónomas-, organizaciones sociales-asociaciones ecologistas-, así como usuarios y beneficiarios individuales. Las alegaciones se dirigieron a múltiples aspectos técnicos territoriales, sociales, económicos, urbanos, ecológicos y medio ambientales.

A partir de ese proceso, se redactan finalmente los proyectos concretos que, a su vez, volvieron a ser expuestos a información pública, incluyendo en esta ocasión la exposición de maquetas del proyecto y sesiones expositivas. Se debe señalar que este intenso proceso de exposición pública tuvo como consecuencia que no existiera ningún rechazo ni oposición destacable durante la construcción de los distintos tramos del nuevo cauce o, al menos, así se percibe por una parte importante de los agentes implicados.

El nuevo cauce correspondiente a la provincia de Alicante fue dividido en cinco tramos: dos fuera de los límites urbanos -desde Beniel a Benejuzar, de Benejuzar a Rojales y entre Rojales y Guardamar- y dos proyectos de encauzamiento urbano correspondientes a las poblaciones de Orihuela y Rojales. Esa misma distinción condiciona la financiación de los proyectos ya que los tramos territoriales fueron sufragados por la Dirección General de Obras Hidráulicas del Ministerio de Obras Públicas, Transporte y Medio Ambiente, mientras que los dos tramos urbanos en Orihuela y Rojales fueron financiados por la Generalitat Valenciana.

\section{III.2 Orihuela}

Orihuela es la capital administrativa e histórica de la comarca de la Vega Baja. Con una población de más de treinta y ocho mil habitantes en el centro urbano y noventa mil en el término municipal, es el sexto municipio por población de la Comunidad Valenciana, inmediatamente detrás de Torrevieja, que ha crecido en las últimas décadas hasta superar los cien mil habitantes en fechas recientes. 
La historia de la ciudad ha estado siempre unida al río Segura y a la huerta, como lo atestiguan los textos históricos y, posteriormente, las cartografías existentes a partir del siglo XIX. El asentamiento origen de la ciudad se localiza en la margen izquierda del río, en torno al Oriolet en la Sierra de Orihuela y el Monte San Miguel; emplazado estratégicamente en la ladera de dicho monte, elevada sobre el nivel del río y protegida de sus avenidas; aunque durante las diferentes fases de crecimiento, va ocupando lugares más bajos de la llanura. Hasta la Edad Media el río Segura constituía una parte del límite amurallado de la ciudad, de modo que solo existía extramuros el llamado Arrabal del Puente o de la Morería (año 1272), conectado por un único puente (Puente viejo) hasta 1430 año en el que se construye el puente Nuevo (CANALES, 1992).

Figura 6. Recorrido conocido como "vuelta a los puentes" grafiado sobre el plano de Francisco Coello, 1859. Orihuela (izquierda). Vista aérea del Azud de las Lavanderas en Orihuela

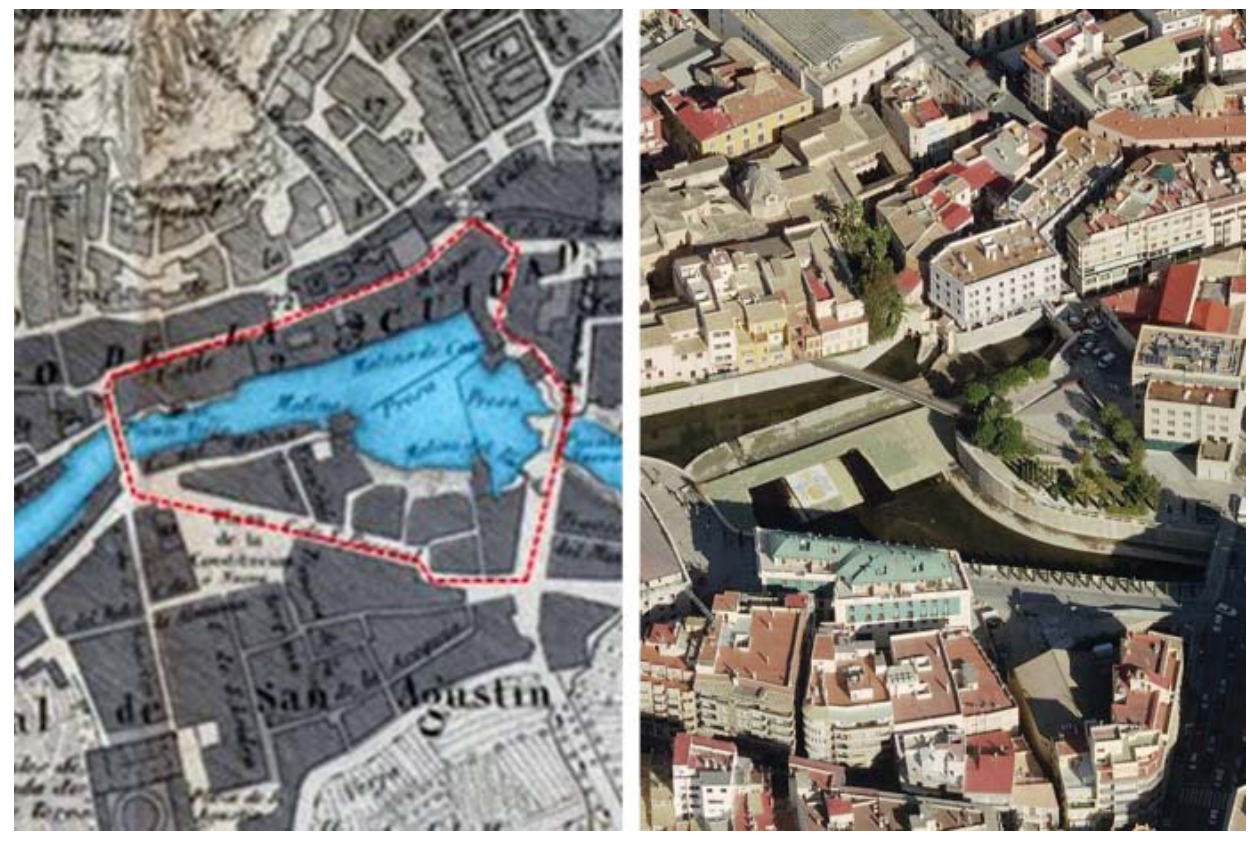

FuENTE: Elaboración propia sobre la cartografía de Coello (izquierda). Bing Maps (derecha).

En los S. XVII - XVIII la ciudad crece en la margen derecha del río, generándose un centro de actividad entorno a la Plaza Nueva, que constituirá desde entonces el núcleo administrativo y económico de la ciudad con la existencia del Ayuntamiento y del Pósito del Trigo, y la celebración habitual de fiestas y ceremonias públicas en dicho espacio (CANALEs, 1992). 
A pesar de que el río Segura es un elemento determinante en el desarrollo histórico de la ciudad, no ha sido un elemento integrador en la definición de su trama urbana. El régimen de avenidas periódicas que constituía la fertilización de la huerta, se transformaba en un riesgo real para la ciudad y sus habitantes. Este factor es decisivo en el hecho de que los edificios históricos hayan dado la espalda al río; y, no ha sido hasta fechas recientes, cuando la mentalidad urbana en cuanto a la construcción de los espacios públicos y las fachadas de los edificios se hayan abierto al río, integrando, al menos parcialmente, nuevos equipamientos entorno al cauce a su paso por el casco urbano.

Un ejemplo de esa falta de valoración del río Segura en la trama urbana de Orihuela es la denominada "vuelta a los puentes" que durante décadas, y hasta la actualidad, ha formado parte de la vida social de la ciudad: un itinerario circular Puente viejo o de Poniente, calle San Pascual, Puente Nuevo o de Levante, calle Alfonso XII y calle Mayor- que describe un recorrido alrededor del río, por calles paralelas al mismo, y que sólo lo encuentra en los puentes, como punto de cruce y visual sobre el mismo (Figura 6). Es decir, el espacio público principal de la ciudad histórica y la conformación de la trama urbana ha dado sistemáticamente la espalda al río.

\section{2. a La trasformación del río tras las riadas de 1987}

Tras las del último tercio del siglo pasado, se propone desviar el trazado del río Segura por el sur del casco urbano, llevando el curso al Reguerón, azarbe mayor o canal de avenamiento que discurre por el Sur del valle, a una distancia de entre dos y tres kilómetros en paralelo al recorrido del río por la ciudad. Sin embargo, esta opción se desestimó, fundamentalmente por razones políticas, con el argumento de que desaparecía la imagen del río atravesando la ciudad. En cualquier caso era el Juzgado Privativo de Aguas de Orihuela y sus regantes quienes tenían que dar su beneplácito, dado que en los Azudes de Almoradí y Callosa se encuentran en el centro de la ciudad (ROCA DE TOGORES, 1832); y dicha propuesta suponía cambios en el diseño de abastecimiento de las acequias a las que sirven. (ANDREU, 2007) 
Figura 7. Orihuela. Fotografías del cauce del río Segura a su paso por el casco ur bano en el Azud de las lavanderas. Comparativa imagen 1987(inundación previa al Plan de Avenidas) y 2005 (tras las intervenciones de remodelación del cauce)

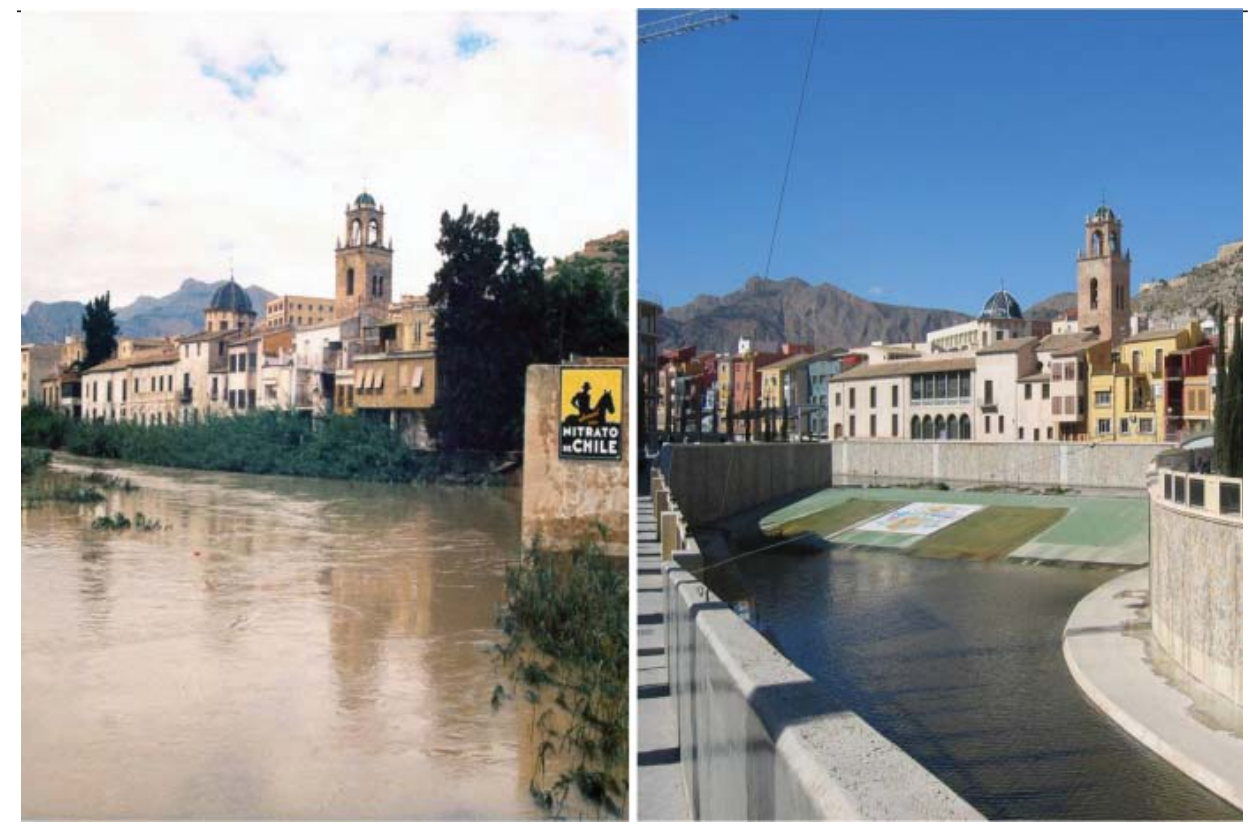

FuENTE: Archivo de los autores

Las obras de encauzamiento realizadas han favorecido la transformación urbana, no solo del propio cauce del río sino de todo su entorno en los dos márgenes. En el año 1993 la Confederación Hidrográfica del Segura (CHS) cede unos $37.000 \mathrm{~m}^{2}$ del dominio público hidráulico del río a su paso por la ciudad. El espacio urbano "liberado" por el encauzamiento del río Segura ha sido objeto de mención y estudio a lo largo de los procesos de revisión del planeamiento (RoDRíguez, 2000). La finalidad de las actuaciones es completar la red de espacios libres y áreas peatonales públicas de la ciudad; además, se establece la limitación de que no se pueda ocupar con ninguna construcción de carácter privativo. (RIQUELME, 2007)

En el casco urbano de Orihuela las actuaciones relacionadas con el encauzamiento y su integración, desde 1987, han consistido en:

- Obra civil del encauzamiento: Actuación a lo largo de 1625 metros lineales, de un vaso de hormigón estanco con una capacidad máxima $400 \mathrm{~m}^{3} / \mathrm{s}$ prevista, realizado por la Confederación Hidrográfica del Segura y financiado por la Generalitat Valenciana. (años 1990-91) (CALVo, 1996) 
- Reurbanización de las márgenes del río entre el Puente Viejo y Puente del Rey: Ayuntamiento de Orihuela y Generalitat Valenciana, bien por inversión directa, bien a través de concesiones administrativas como el aparcamiento Entrepuentes. (años 1998-99)

- Construcción de varios nuevos puentes (tráfico rodado) o pasarelas peatonales: (ordenado según su posición desde aguas arriba)

- Puente de las Salesas: 2005-06. Ayuntamiento de Orihuela.

- Pasarela de Las Salesas: 1970. Reconstruida 2001. CHS

- Pasarela del Palacio del Obispo: Ayuntamiento de Orihuela

- Pasarela del Casino: Ayuntamiento de Orihuela. 2002.

- Puente de la Trinidad - Pasarela de los Arcos: CHS.

- Puente del Rey: CHS .1990.

- Puente de la circunvalación - CV903: GVA

- Restauración de fachadas y cubiertas en ambos márgenes del río entre el Puente viejo y el Puente Nuevo: Ayuntamiento de Orihuela, $1.891 \mathrm{~m}^{2}$. (año 2000) (Figura 7 y 8 )

Figura 8. Orihuela. Fotografías del cance del río Segura a su paso por el casco urbano desde el puente Viejo. Comparativa imagen 1985 y 2005 (tras las inter venciones de remodelación del cauce)
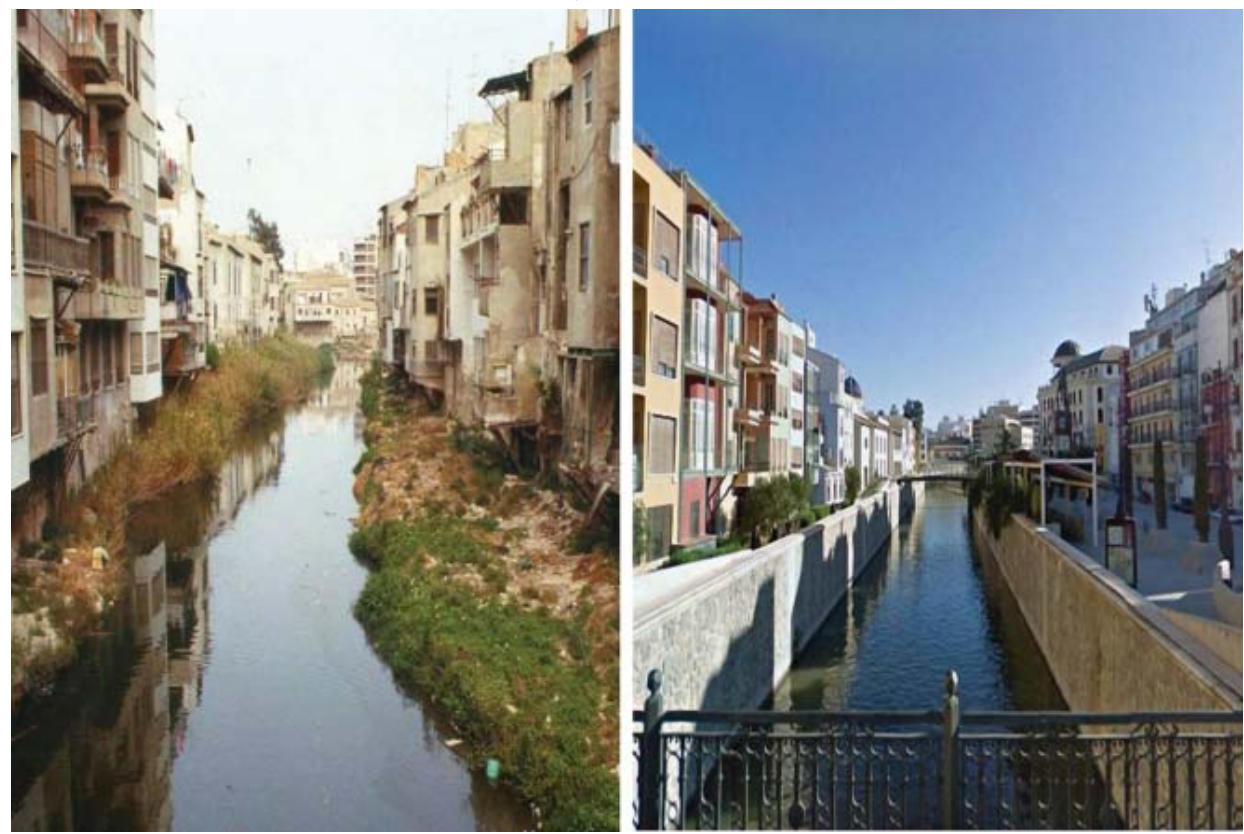

FuENTES: Archivo de los autores 
En este sentido, se ha producido una intervención de las diferentes administraciones en el acondicionamiento del nuevo espacio urbano producido por el nuevo encauzamiento. Así, la Confederación Hidrográfica del Segura se hace cargo de los nuevos encauzamientos y de la obra civil en las márgenes del propio cauce en las afueras del ámbito urbano, tanto aguas arriba como abajo. Por el contrario, las actuaciones de acondicionamiento urbano en los márgenes del río, dentro del casco urbano, las realiza el Ayuntamiento de la ciudad. Por su parte, la intervención de la Generalitat Valenciana ha apoyado iniciativas, tanto en la financiación de puentes en el cauce, como en el acondicionamiento de edificios relevantes como el Palacio Episcopal, y también en la regeneración y adecuación de diversos espacios adyacentes al propio cauce (Figura 9).

También la iniciativa privada ha tenido participación en la transformación urbana de Orihuela, especialmente en la urbanización y acondicionamiento de los jardines situados en la margen sur en el centro urbano sobre un aparcamiento de dos plantas. La fórmula utilizada para la construcción del aparcamiento, la urbanización del entorno y los jardines situados en el exterior es una concesión administrativa en explotación.

Una actuación adicional, fruto de la colaboración Generalitat - Ayuntamiento, fundamental para garantizar un equilibrio en el cauce, fue la puesta en servicio en 1996 de la E.D.A.R. de Orihuela - Molins, para el casco urbano de la ciudad. Además de la actualización y mejora de la capacidad de una infraestructura del año 1975, se diseñó un punto de vertido en el Azud de las Lavanderas, de agua tratada y depurada, de manera que se garantizara un caudal ecológico que mantuviera mínimamente unas condiciones salubres para este tramo del río (Aqualia, 1996).

Otra de las actuaciones realizadas por la Confederación Hidrográfica del Segura en 2007 fue la instalación de unos "inyectores de oxígeno", mediante aspersores, que paliaran los malos olores derivados del estancamiento de las aguas; se trata de una solución ya apuntada desde la década de los noventa (PARRA, 1998). Esta misma actuación se realizaría en 2009 en el tramo del río entre Benejúzar y Rojales, con resultados muy positivos, según opinión de los agentes implicados. 
Figura 9. Cartografias del centro urbano de Orihuela (superior) y Rojales (inferior).

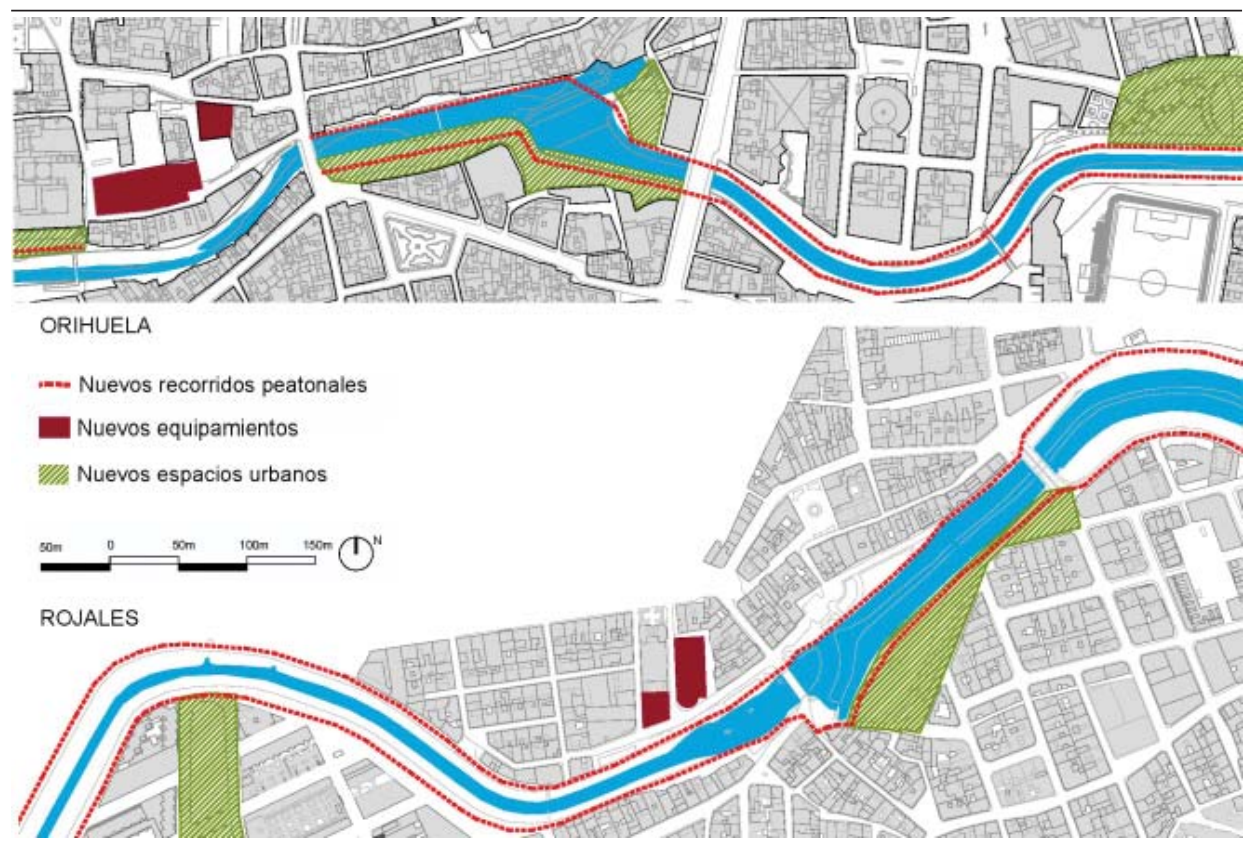

FUENTE: Elaboración propia

\section{III.3 Rojales}

Al igual que Orihuela, Rojales históricamente ha estado vinculado al río Segura, de hecho el único puente que existía a través del río Segura en Rojales data de 1790, según consta en el propio puente, y responde a un recorrido de carácter territorial.

Al igual que en Orihuela, a raíz de las inundaciones de la década de los ochenta del pasado siglo se ponen en marcha la ejecución de un nuevo cauce tanto en el ámbito urbano como en los límites de éste, donde se suprimen un importante número de meandros para aumentar la pendiente del río $\mathrm{y}$, por tanto, el desagüe en caso de crecida. 
Figura 10. Rojales. Fotografias del cauce del río Segura a su paso por el casco urbano. Crecida del río a su paso por el puente Carlos III (izquierda). Imagen del puente Carlos III año 2013 (derecha).

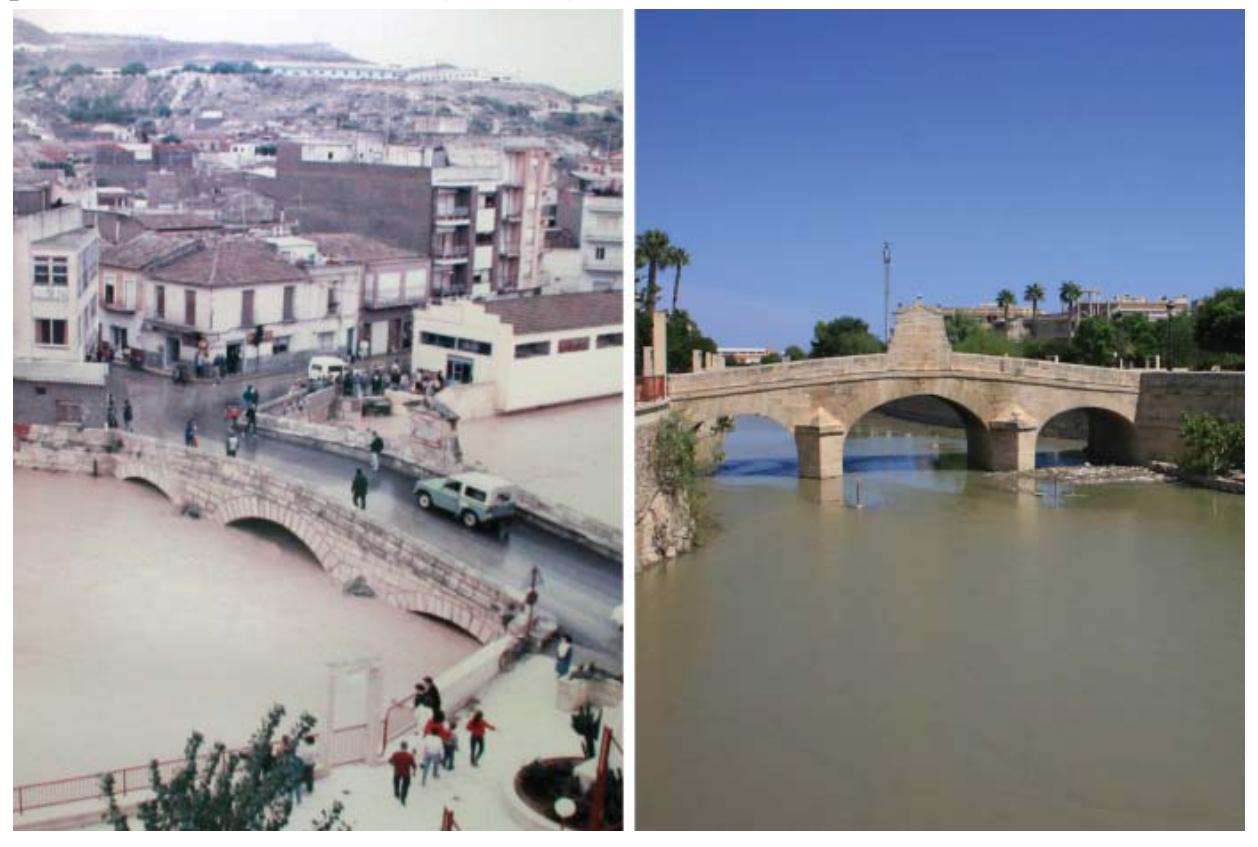

Fuentes: Ayuntamiento de Rojales y elaboración propia

La transformación del cauce se realiza a lo largo de los años 1990 y 1991. En esta ocasión se vuelven a dar cita las tres administraciones: el Estado, a través del Ministerio de Obras Públicas -Confederación Hidrográfica del Segura- se hace cargo del encauzamiento del ámbito no urbano, la administración autonómica, la Generalitat Valenciana -y la Consellería de Obras públicas- la que se encarga de las obras de encauzamiento del río a su paso por la zona urbana de Rojales; y la administración local, el propio ayuntamiento que financia todas las obras de urbanización de los márgenes urbanos del río, en un recorrido de 1.527 metros de longitud a lo largo del río (Figura 9).

La intervención del encauzamiento incluye, también, nuevas comunicaciones entre los dos márgenes del río. Así, se construyeron una pasarela peatonal que unía los nuevos espacios ganados y urbanizados como zonas de paseo y estanciales. Igulamente, se lleva a cabo la construcción de un nuevo puente rodado que comunica las áreas situadas al norte y sur del río Segura; se trata de un nuevo puente que, además de reforzar las relaciones urbanas de Rojales, resolvía la comunicación territorial del entorno evitando el paso por el único puente existente 
hasta la fecha. Es muy posteriormente -finales del siglo XX-cuando se construye el tercer puente que une el territorio de la Vega Baja del Segura situado a las dos márgenes del río, el Nuevo Puente Reina Sofía.

La actuación propiamente dicha permite una mayor seguridad frente a las avenidas y crecidas. Sin embargo, existen tres aspectos complementarios que influyen en la configuración de la ciudad y que, aunque no forman parte de la estricta solución técnica, no hubieran sido posibles sin la obra del nuevo cauce. Así destacan: la creación de paseos y jardines junto al río; el uso de nuevos espacios verdes junto al casco urbano en los antiguos meandros; $y$, la reconfiguración urbana de actividades y usos.

Respecto al primer aspecto, la creación de paseos y jardines junto al río, se puede comprobar a través de las fotografías aéreas (Figuras 4 y 5) como la intervención ha supuesto el acondicionamiento de las márgenes del río para el uso peatonal. El cambio es cuantitativa y cualitativamente sustancial ya que anteriormente no existía ningún espacio público entre las traseras de la edificación que recaía al río y el propio cauce; de hecho, en la actualidad, es posible recorrer peatonalmente las dos márgenes del río en todo el tramo urbano, contabilizándose más de 2.500 metros lineales de paseo nuevo teniendo en cuenta ambas márgenes del río.

Figura 11. Rojales. Fotografias de nuevos espacios urbanos y nuevos equipamientos construidos tras el encauzamiento del río Segura a su paso por el centro urbano.

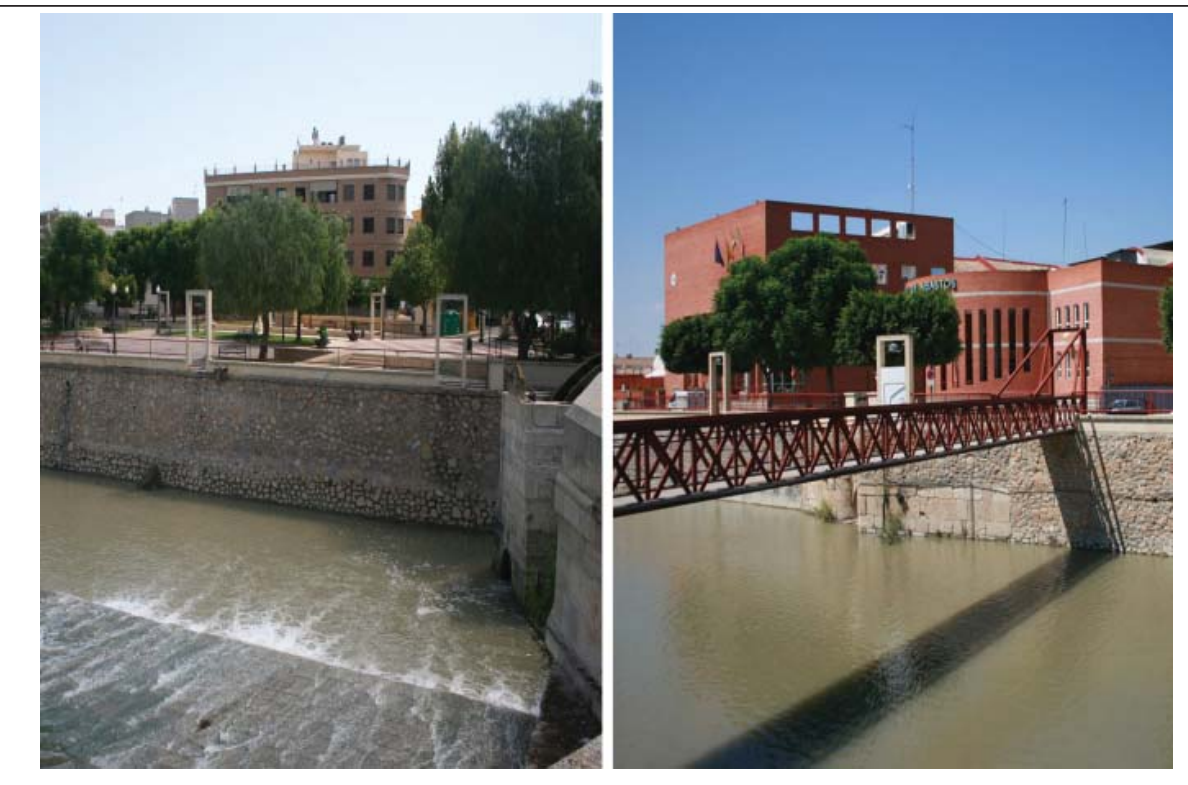

FUENTES: Elaboración propia 
Además de la circunstancia anterior, el segundo aspecto mencionado vincula esos recorridos peatonales a la incorporación de nuevos espacios ajardinados, tanto en el centro urbano como en las afueras. En el centro urbano destaca la creación de los jardines junto al puente de Carlos III y la Noria de la Bernarda en el azud de Rojales. Se trata de un nuevo espacio de $7.000 \mathrm{~m}^{2}$ en pleno centro urbano que antes ocupaban los taludes del antiguo cauce del Segura. El otro tipo de espacios verdes de nueva creación son los dos antiguos meandros del río en las afueras de la población. En el caso de Rojales la proximidad de tres meandros al casco urbano -dos aguas arriba y uno hacia la desembocadura- supone la oferta de nuevos espacios verdes acondicionados junto a la población.

Por último, el tercer aspecto relevante, se centra en la reconfiguración urbana de actividades y usos, abarcando nuevos usos, recualificación de usos existentes y nueva valoración del río en el entorno urbano. Destaca la nueva ubicación de equipamientos en el frente fluvial, algunos que ya estaban vinculados al río en otro lugar como el mercado, pero otros que se encontraban en el interior del núcleo urbano y que tras la intervención se construyen en el frente fluvial de Rojales, como el nuevo Ayuntamiento del municipio. (Figura 11) Otra transformación urbana es la diferente relación entre la edificación recayente al cauce, que antes configuraba una sucesión de traseras sin cualificar y se transforman en frentes de fachada que cualifican el nuevo espacio fluvial. Además, al igual que en Orihuela ese proceso está acompañado por un destacado incremento de los precios del suelo en aquellos solares recayentes al frente del río.

\section{EVALUACIÓN DE LA ACTUACÍON}

Las actuaciones han sido evaluadas a partir de encuestas realizadas a un número reducido, pero representativo, de agentes implicados. Se ha entrevistado, al menos, a un representante de cada uno de los siguientes sectores: políticos, técnicos, empresarios y representantes sociales.

Tanto en el caso de Orihuela como en el de Rojales las encuestas han puesto de manifiesto un cierto consenso en la precepción de las intervenciones, aunque se aprecian claras diferencias dependiendo de los agentes encuestados que conviene subrayar.

Respecto a la encuesta realizada y según los epígrafes definidos: 


\section{IV.1 Percepción del lugar:}

En el caso de Orihuela, pese a que la encuesta realizada se centra en el tramo urbano, mayoritariamente todos los encuestados hablan de dos tramos diferenciados y en ambos casos con una visión positiva:

1. Fuera del casco urbano de Orihuela: La transformación del río aguas arriba, entre Beniel (Murcia) y Orihuela, ha favorecido la recuperación de un corredor natural sobre las motas del río Segura, con la adecuación del área de terreno de alguno de los meandros rectificados en el Plan de avenidas, como zona estancial; así los ciudadanos en general utilizan estos ejes como espacio para hacer deporte al aire libre, paseo en bicicleta o caminar, de manera que popularmente se conoce como "ruta del colesterol".

2. Dentro del recorrido urbano: La transformación urbana se percibe también de manera positiva, la celebración de diferentes eventos locales en estos nuevos espacios, como por ejemplo en la plaza de la Centuria Romana, ha hecho que se vayan integrando en los recorridos habituales de los ciudadanos; todo ello, pese a que no existe la fortaleza de un continuo urbano de bajos comerciales o instituciones que tengan un acceso directo desde la fachada del río, ya que en Orihuela el volumen edificado junto al río Segura acota y cierra el espacio urbano.

En el caso de Rojales todos los agentes entrevistados coinciden en afirmar la bondad que han supuesto las diferentes actuaciones en el entorno del cauce del río a su paso por el casco urbano. En este sentido se percibe con claridad la mejora de la imagen urbana general y del atractivo del río como espacio para actividades ciudadanas. Aunque el cauce del río Segura tenga un ancho similar que en Orihuela, la diferencia sustancial son los espacios urbanos adyacentes al mismo, que en el caso de Rojales son mucho más amplios, llegando a producirse entre las fachadas a ambos lados del río, entre la calle del Malecón y la calle del Carmen hasta $124 \mathrm{~m}$ de visual, lo que unido a una tipología edificatoria de baja altura en general, da a la ciudad un espacio privilegiado en cuanto a su espacialidad.

Resultan significativas algunas afirmaciones que evidencian esa valoración positiva en expresiones como "ahora la gente sale a andar por el río" o la misma denominación anterior de "ruta del colesterol" a los nuevos recorridos peatonales junto a las dos márgenes del río; que mientras que en Orihuela se producen fuera del casco urbano, en Rojales constituye un paseo dentro del ámbito urbano. 
En el caso de Orihuela se reconoce la mejora en la seguridad con respecto al riesgo de inundaciones, dado que ha habido crecidas del río en las que las obras realizadas han sido efectivas y pese a la intensidad de flujo no se produjeron grandes problemas en el casco urbano, y de esta manera la población tomó consciencia de la efectividad de dichas mejoras. No obstante, se reconoce que el riesgo, aunque controlado en ciertos niveles, sigue existiendo.

En Rojales sin embargo, la percepción sobre el control y seguridad de riadas futuras no es tan unánime, destacando algunas de las opiniones en las que se constata que la preocupación sobre las posibles crecidas del río sigue existiendo. Así se puede señalar que la población y los políticos siguen mostrando una preocupación por nuevas inundaciones mientras que los técnicos aprecian una mayor seguridad y control, aunque admiten que no puede existir una garantía total.

\section{IV.2 Carácter integrado y transversal de las actuaciones:}

Debido a la singularidad de la intervención que, como se ha comentado, inicialmente tenía un carácter territorial con afecciones urbanas, la transformación del río ha exigido la participación de las diferentes administraciones públicas. En este epígrafe se evidencian dos aspectos complementarios en relación con la integración de las políticas urbanas: por un lado, entre las diferentes escalas o intervenciones temáticas y, por otro lado, entre las políticas realizadas por diferentes administraciones en un resultado final. En ambos casos se evidencia una percepción opuesta entre técnicos y políticos, por un lado, y el resto de la población no especializada, por el otro.

Los primeros, por estar directamente afectados, conocen con precisión el detalle de las distintas actuaciones que confluyen en la transformación del río o el reparto de responsabilidades entre las distintas administraciones; sin embargo, para la población no especializada no existe una especial distinción entre las obras parciales que constituyen la actuación, ni identifican la financiación de las distintas administraciones.

Por tanto, para la población en general, las obras se han realizado y no se cuestiona si ha sido una única administración la responsable de las mismas o se ha tratado de una actuación integrada y cofinanciada.

Cuando se señalan descoordinaciones o falta de integración en las políticas estas manifestaciones provienen de los políticos y los técnicos. Entre ellos se identifica a su vez una pequeña diferencia de interpretación ya que mientras los técnicos observan la descoordinación con mayor naturalidad los políticos siem- 
pre relacionan esa descoordinación con la participación de un partido político diferente al que ellos pertenecen.

\section{IV.3 Grado de trascendencia de las actuaciones realizadas, más allá de la escala urbana de las mismas y carácter innovador de las mismas:}

Desde todos los ámbitos encuestados se considera que las actuaciones han sido muy relevantes a nivel local, por resolver un problema histórico como es el del riesgo de inundación que venían sufriendo, por lo que se ha entendido desde ese punto de vista la alta trascendencia de las mejoras.

Por otro lado, a nivel técnico o especializado, se percibe una visión más amplia de esta cuestión, en ningún caso se estima que las actuaciones aporten ninguna innovación que pueda trasladarse como ejemplo a otros ámbitos similares: es decir, que las propuestas se enmarcan dentro del tipo de soluciones ensayadas y habituales en numerosos cauces urbanos. La singularidad de determinadas soluciones está más relacionada con la tipología de materiales utilizados en el momento del proyecto. Desde ese punto de vista, las actuaciones de ajardinamiento y equipamiento de los espacios públicos en Orihuela, fundamentalmente en el entorno acotado entre el Puente viejo y el Puente Nuevo, y prolongado hacia la pasarela de los Arcos aguas abajo, y hacia la plaza de la Universidad y el PROP aguas arriba, son las piezas más contemporáneas en cuanto a mobiliario y materiales.

\section{IV.4 Sostenibilidad ambiental:}

Tanto en Orihuela como en Rojales se percibe de manera general la mejora en espacios verdes, al igual que la disminución en los niveles de contaminación ambiental. En cuanto a la mejora de la calidad del agua, sí que se admite una mejora con respecto a la situación anterior, fundamentalmente desde que entraron en funcionamiento distintas plantas depuradoras aguas arriba, Murcia entre otras; pero aun así, se reclama mayor control y una mayor dotación para el caudal ecológico mínimo. Con respecto al ahorro energético no se valora como algo trascendente o mejorado sensiblemente con todas las correcciones realizadas.

\section{IV.5 Repercusión en la ciudad:}

En ambos casos, como se ha adelantado en apartados anteriores, la percepción de la población en general, tanto del río como de las actuaciones urbanas en el espacio público, que trasciende a partir de las encuestas realizadas, sí es 
claramente positiva. Se percibe como áreas seguras, atractivas como espacios de conectividad, más en general en Rojales que en Orihuela, en que hay tramos diferenciados dentro del mismo recorrido urbano.

En el caso de Orihuela la actividad comercial no se ha incrementado en estas áreas, salvo por algún caso puntual; pero hay que considerar que algunos de los solares clave pertenecientes a manzanas con fachada al río se han quedado sin construir o con la obra a medio hacer debido a la crisis actual. Pero incluso considerando la coyuntura económica actual, la percepción en general que transmiten los encuestados es la potencialidad de las zonas transformadas, a futuro.

\section{IV.6 Implicación de la sociedad civil: Durante los diferentes procesos de actuación sobre el río y su entorno:}

La mayoría de los encuestados apuntan a la plataforma Comisión Pro-Río como uno de los agentes sociales más implicados y reivindicativos en lo relativo a todos los problemas que el río Segura ha supuesto a su paso por las distintas poblaciones y territorios.

Esta plataforma de carácter civil denominada Comisión Pro-Río, con sede en Orihuela, se ha encargado, desde el año 1999, de la denuncia sistemática de todas aquellas cuestiones que afectan al río Segura: vertidos ilegales, extracción no autorizada de agua de pozos del acuífero, contaminación de las aguas de riego, defensa del ecosistema fluvial, etc, y de apoyo a aquellas iniciativas de sensibilización relacionadas con el río Segura (MuÑoz, 2002). Sus iniciativas están bien valoradas o tienen buena acogida en general, y sí se percibe una cierta influencia en algunas cuestiones que se han difundido a través de la prensa local, como el hecho de personarse como acusación popular en casos de denuncia de contaminación por vertidos incontrolados en el río, entre otras causas.

Igualmente, cabe mencionar otras agrupaciones sociales cuya actividad ha llevado la problemática del río Segura a la sociedad como son las plataformas Segura Limpio y Cauce Abajo. Incluso llevando sus iniciativas ante los tribunales de justicia (DE GEA, 1999).

\section{IV.7 Valoración global:}

Como conclusión o valoración final a esta encuesta, la visión que se nos traslada como "puntos fuertes/oportunidades potenciales" y "puntos débiles/amenazas" en el contexto del entorno urbano del río, a su paso por el centro de la ciudad, se han desgranado en las primeras cuestiones planteadas en la encuesta. 
Hay muchos puntos coincidentes entre ambos municipios: con respecto a las potencialidades o puntos fuertes, la recuperación de los ejes en ambas márgenes del río a su paso por el casco urbano, como áreas de conectividad, de refuerzo de la vida social o de los acontecimientos de la ciudad, como áreas de expansión o de introducción del zonas verdes adyacentes que dotan al centro de ajardinamiento o plazas de recreo que mejoran la imagen de la propia ciudad. En el caso de Rojales, el hecho de que la fachada urbana continua, así como la ubicación de equipamientos, tengan acceso desde estas áreas dinamiza con más potencia el uso cotidiano de estos espacios públicos. En el caso de Orihuela, la potencialidad existe, pero todavía le falta reforzar, al menos en la zona de más proyección entre el Puente viejo y el Puente nuevo, la definición de la edificación y la ocupación de los edificios que tienen fachada a la Plaza de la Centuria Romana, de manera que se refuerce la conectividad hacia el casco antiguo por la zona de la Universidad (aguas arriba en la margen izquierda) y hacia la Pasarela de los Arcos (aguas abajo en la margen izquierda).

Con respecto a las debilidades observadas y argumentadas por los diferentes sectores entrevistados, se repiten los argumentos que tienen carácter medioambientalista: la calidad de las aguas, el mantenimiento de los caudales ecológicos del río para garantizar su limpieza y el equilibrio del ecosistema.

Además en algún caso se apunta, desde el punto de vista de la definición de los espacios públicos adyacentes, la necesidad de mejora de la escena urbana, interviniendo en la accesibilidad del recorrido y mejorando la conectividad hacia otros espacios públicos representativos de la ciudad, que no están necesariamente relacionados con el río, de manera que los itinerarios urbanos habituales: de carácter turístico, histórico-cultural, comercial-administrativo, etc. conformen una red identificable y que configuren una imagen potente y específica de cada una de las ciudades. Pese a que, al menos en Orihuela, se han construido diferentes pasarelas $\mathrm{y}$, por tanto se ha mejorado la conectividad entre ambas márgenes del río, no se trata de diseños demasiado atractivos ni integrados, y además desafortunadamente tienen una precaria adecuación para los peatones, en términos generales.

\section{DEBATE}

Tanto los textos consultados como las entrevistas realizadas a los agentes implicados evidencian una valoración muy positiva de la actuación en su conjunto, por haber supuesto una clara mejora en la calidad urbana de sus poblaciones. Sin embargo, resulta interesante observar, al menos tres aspectos que no han sido explicitados en esa valoración positiva de las actuaciones. 
En primer lugar, parece necesario recordar que se trata de una intervención vinculada a la ingeniería hidráulica y con un carácter territorial cuyas consecuencias tienen una implicación urbana importante. Así, surgen dos ámbitos diferentes de la actuación que tienen dos escalas de percepción social: por un lado, la mejora técnica -ingeniería hidráulica- de la modificación del cauce del río en la que la participación social es más limitada ante las dificultad de argumentar con otras alternativas; y por otro lado, la transformación urbana y territorial desarrollada en los municipios en la que las posibilidades eran más amplias, aunque los resultados hayan sido claramente bien valorados.

Un segundo aspecto, relacionado con el anterior, es la escasa participación pública en el proceso de transformación urbana acontecido en las dos poblaciones. Seguramente esa reducida implicación en la transformación urbana viene derivado por una realidad contundente: fuera cual fuera el resultado concreto de las intervenciones, la seguridad ante riadas y crecidas ha mejorado notablemente $\mathrm{y}$, por tanto, la actuación es válida. Sin embargo, se han producido importantes cambios en el uso del suelo de las márgenes del río sobre los que la población no tiene una clara percepción, desde un considerable aumento del valor de los inmuebles y solares junto al cauce, hasta una nueva ubicación de actividades urbanas en relación con el río.

Y la tercera cuestión, en el ámbito de las transformaciones urbanas, se sitúa en el papel que estas actuaciones han tenido para las dos poblaciones. Es cierto que han mejorado el paisaje urbano de las poblaciones y han mejorado los espacios adyacentes pero no se ha abordado como una actuación estructural que afectase al conjunto de la población. Dicho en otros términos, teniendo en cuenta que el cauce del río Segura cruzaba totalmente las dos poblaciones y, por tanto, tiene un carácter estructural desde el punto de vista urbano, las actuaciones acometidas han puesto de manifiesto la fragmentación y la discontinuidad de la intervención, perdiendo la posibilidad de trascender en mayor medida la transformación urbana.

\section{PARTE PROPOSITIVA}

En el ámbito de las propuestas de mejora en la gestión de las políticas urbanas como las analizadas aparecen dos cuestiones que, aunque complementarias, forman parte de una cultura de relación entre las administraciones y la ciudadanía que debe ser mejorada: por una parte una mayor participación de la población en las políticas urbanas y, por otro lado, una mejor explicitación de las responsabili- 
dades y compromisos de cada una de las administraciones estatales, autonómicas, provinciales y locales.

En relación con la participación pública conviene mencionar que cuando nos referimos a las estrategias de participación no nos referimos a la tradicional información pública sino que la participación, entendida en su sentido más amplio, además de la información a lo largo de todo el proceso de desarrollo de una política urbana, debe incluir la corresponsabilidad de las de las decisiones tomadas según un proceso participativo. En este sentido las transformaciones llevadas a cabo en estas ciudades han sido planteadas desde arriba (poderes públicos estatales) hacia abajo (corporaciones locales y ciudadanos). Es indiscutible que han existido procesos de información pública, fundamentalmente los públicos especializados o técnicos, pero no una corresponsabilidad e implicación por parte de la ciudadanía en las decisiones tomadas.

El otro aspecto mencionado se refiere a la explicitación de las acciones que llevan a cabo las administraciones públicas y su participación. Es decir, los ciudadanos no perciben con claridad qué administración hace qué obras y la relación entre las distintas administraciones. Esta cuestión parece más que nunca pertinente, precisamente en un momento social de discusión sobre la existencia de cuatro niveles de administración. En el caso concreto de las actuaciones estudiadas, resulta muy complejo averiguar e identificar la financiación y responsabilidad de cada una de las administraciones participantes. Más aún, cuando una parte de las intervenciones que corresponden inicialmente a una administración, a su vez, se financian por parte de otras. Uno de los distintos ejemplos de este proceso es el caso de obras que debe financiar la administración local pero ésta, a su vez solicita, financiación de la Diputación provincial, diluyendo responsabilidades y autorías. En este sentido, mejorar la explicitación y comunicación de la participación y responsabilidad de cada una de las administraciones actuantes permitiría una mejor valoración social de las mismas.

\section{CONCLUSIONES GENERALES}

En los apartados anteriores se han estudiado las actuaciones urbanas y su percepción social de acuerdo con las particularidades de cada una de las circunstancias urbanas y territoriales. También se ha indicado que esa percepción tenía sus matices en función de los agentes entrevistados. En este apartado se propone una valoración sintética que integre tanto las aportaciones técnicas y científicas como los resultados del trabajo de campo, a través de las encuestas. En este sen- 
tido, se propone la siguiente tabla de valoración (cuadro 2), a modo de resumen sintético de las actuaciones realizadas:

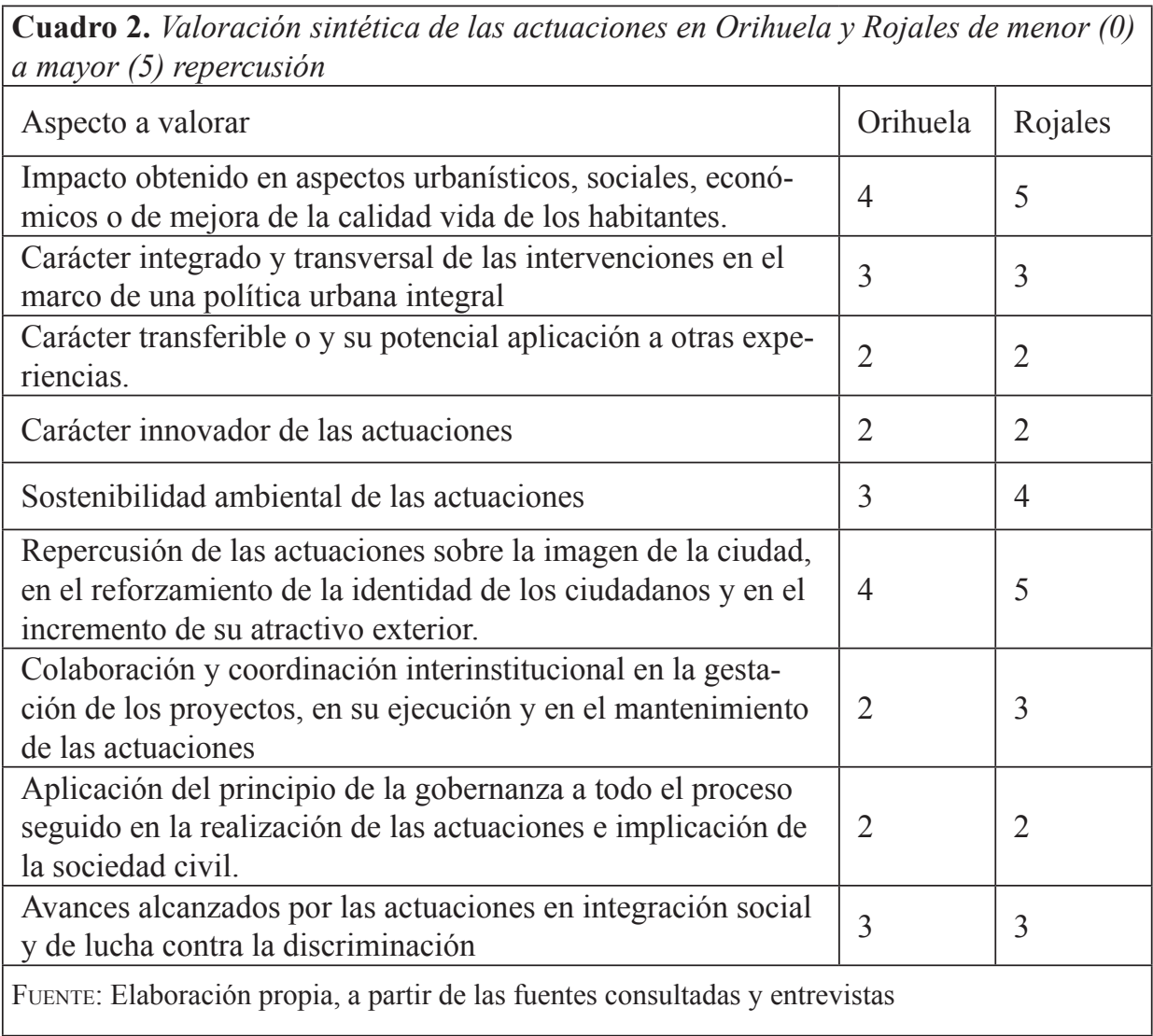

\section{BIBLIOGRAFÍA}

Andreu, J. (2207): “La CHS ultima el anteproyecto de desvío del río Segura por el cauce del Reguerón”. La Verdad, 22 de diciembre de 2007. En línea: http://www. laverdad.es/alicante/20071222/orihuela/orihuela-ultima-anteproyecto-desvio-20071222.htm 1, consultado el 9/08/2013.

Aqualia (1996): EDAR Orihuela - Molins. Tríptico informativo 1996. En línea: http:// www.aqualia-infraestructuras.es/media/docs/EDAR\%20de\%20Orihuela.pdf, consultado el 20/08/2013. 
Calvo García-Tornel, F. (1996): "Las transformaciones de los espacios urbanos fluviales en zonas áridas: lecciones de la cuenca del Segura”. Documents d'Anàlisi Geogràfica, no $31,103-116$.

Canales Martinez, G. (1992): "Procesos de formación urbana de Orihuela (Alicante)". Revista Investigaciones Geográficas, nº10. 143-164

Coello, F. (1859). Cartografía de Orihuela. E 1/10000. En línea: http://www.alicantevivo.org/2008/12/mapas-de-coello-de-la-provincia-de.html, consultado el 20/08/2013

Ezcurra Cartagena, J (1995): “Encauzamiento del Río Segura desde la contraparada (Murcia) hasta la Guardamar del Segura (Alicante) y recuperación de los sotos del río. España". Revista de Obras Públicas, no 3.341.

GARCíA MAYOR, C et al.(2012): "Los valores territoriales y paisajísticos de la Huerta de Murcia y la Vega Baja del Segura", en Patrimonio hidráulico, industrial, arquitectónico y urbano en el ámbito hispano - cubano . Fontana, Melgarejo y Zardoya (Eds.). CRACE. 295-320.

de Gea Cayuelas, E. M. (1999): "El río Segura: un fracaso político-ciudadano". Revista Alquibla $\mathrm{n}^{\circ}$ 5. 637-644.

Generalitat Valenciana, Consellería de Medio Ambiente, Agua, Urbanismo y Vivienda (2011): Estrategia Territorial de la Comunidad Valenciana. Valencia, Generalitat Valenciana.

Gil Olcina, A. y Morales Gil, A. (eds.) (1989): Avenidas fluviales e inundaciones en la cuenca del Mediterráneo. Alicante, Instituto Universitario de Geografía de la Universidad de Alicante

Gil Olcina, A; Olcina Cantos, Jorge; y Rico Amorós, A. M. (eds.) (2004): Aguaceros, aguaduchos e inundaciones en áreas urbanas alicantinas. Alicante, Universidad de Alicante

Gomez Ordóñez, J. L. y Grindlay Moreno, A. L. (dir). (2008): Agua, Ingeniería y Territorio. La transformación de la cuenca del río Segura por la Ingeniería Hidráulica. Madrid, Ministerio de Medio Ambiente, Medio Rural y Marino. Confederación Hidrográfica del Segura.

Grindlay Moreno, A. L. y Hernández Gómez-Arboleya, E. (2007): “Las infraestructuras hidráulicas en la cuenca del Segura", en V Congreso Nacional de la Ingeniería Civil. Sevilla, Colegio de Ingenieros de Caminos, Canales y Puertos.

Instituto Cartográfico Valenciano. En línea: http://www.icv.gva.es/, consultado el 02/09/2013

MARTí Ciriquí́n, P. (2006): "Las transformaciones y emergencias en el territorio de las comarcas del sur alicantino: la presión de la segunda residencia en el litoral", en La ciudad fragmentada. Nuevas formas de hábitat. Publicaciones PONCE HERRERO, G. (ed.). Alicante. Universidad de Alicante. 131-165.

Ministerio de Hacienda y Administraciones Públicas. En línea: http://www.catastro. meh.es/, consultado el 02/09/2013

MuÑoz BRAvo, J. (2007): “Encauzamiento del río Segura en Orihuela" en Plan de defensa de 1987 frente a avenidas en la cuenca del Segura. XX Aniversario. Murcia, Confederación Hidrográfica del Segura. 297-307 
Muñoz Grau, J.A. (2002): “El quinto elemento". Revista Alquibla no 8. 803-805.

Olcina Cantos, J. y Giménez Ferrer, J. M. (2002): "Riesgo de inundaciones en tierras alicantinas. Método y resultados". Revista Nimbus n ${ }^{\circ}$ 9-10; 99-124.

PArra Ruíz, J. (1998): “Canalización del río Segura y sus improvisaciones”. Revista Alquibla $\mathrm{n}^{\circ}$ 4. 673-675.

Patricova. Plan de Acción Territorial de Carácter Sectorial sobre Prevención de Inundación enla Comunidad Valenciana. En línea: http://www.cma.gva.es/web/indice.aspx? nodo $=76677 \&$ idioma $=$ C, consultado el 25/09/2013

Riquelme, P. (2007): “Guillén (LV) pidió a la CHS el deslinde del dominio público hidráulico del Segura en Orihuela ciudad”. Orihuela Digital, 3 de agosto de 2007. En línea: http://www.orihueladigital.es/orihuela/lv_verdes_guillen_segura_030807.htm, consultado el 10/08/2013.

Roca de Togores y Alburquerque, J. (1832): Memoria sobre los riegos de la Huerta de Orihuela. Valencia, Real Sociedad Económica de la Ciudad y Reino de Valencia.

Rodríguez Carmona, E. G. (2000): “El encauzamiento del río Segura y el nuevo frente urbano de Orihuela. Balance de un cuatrienio "finisecular": 1995-1999. Revista Alquibla n ${ }^{\circ}$ 6. 217-240

Ureña Francés, J.M. et al. (1999): “Ordenación de las áreas fluviales en las ciudades: un enfoque metodológico". Revista del Colegio de Ingenieros de Caminos, Canales y Puertos $n^{\circ} 46$, Río y Ciudad, volumen I. 